\title{
Low Hc and High $\sigma$ s Metal Particles for Magnetic (Recording) Tapes
}

\author{
Noriyuki KITAORI*, Hideo OHKAWARA, Masayoshi SHINODA and Hitoshi OGAWA
}

Received March 2, 1990 ; Accepted July 9, 1990

\begin{abstract}
The magnetic properties and video recording performance of tapes prepared by using acicular metal particles of low coercive force were studied. Metal particles with low Hc were prepared by adding adequate amounts of $\mathrm{Ni}$ and $\mathrm{Co}$, and by thermal surface-oxidation to ensure high stability of metal particles. Coercive force (HC) and saturation magnetization ( $\sigma s)$ of the particles obtained were $935 \mathrm{Oe}$ and $120 \mathrm{emu} / \mathrm{g}$, respectively. The corrosion resistance of the magnetic tape formed using the particles was comparable to or higher than that of commercial $8 \mathrm{~mm}$ video tape. The electromagnetic characteristics were compared with commercial reference tapes. In terms of video recording performance, when measured using a ferrite head, the $R F$ output and $C / N$ levels were $1.8 \mathrm{~dB}$ and $1.6 \mathrm{~dB}$ higher than that of commercial 1/2-inch S-VHS VCR tape at $4.5 \mathrm{MHz}$, respectively, while the $R F$ output level was $2.5 \mathrm{~dB}$ lower than commercial 1/2-inch ED-Beta tape at $7 \mathrm{MHz}$, and the $\mathrm{C} / \mathrm{N}$ level was $1.6 \mathrm{~dB}$ higher when using a TSS head.
\end{abstract}

\section{INTRODUCTION}

Recently, video recording tapes with a coercive force (HC) ranging of 800 to 1000 Oe have been most widely used in many recording systems. This is because tapes having HC of above 1000 De cannot be saturated when they are recorded by using a ferrite head. Co-modified $\gamma-\mathrm{Fe}_{2} \mathrm{O}_{3}$ powder and Ba-Ferrite powder have been used the magnetic materials for the high coercivity tapes. In video recording tapes, the balance between the $\mathrm{HC}$ and the residual magnetic flux density $(\mathrm{Br})$ is important, and the appropriate $\mathrm{Br} / \mathrm{Hc}$ ratio is from 2 to 3 from the data in previous papers $(1,2)$. However, the $\mathrm{Br} / \mathrm{HC}$ ratios of tapes using oxide powder are actually about 1.8 , as the saturation magnetization (os) is relatively low. Hc less than 1000 oe and $\sigma \mathrm{s}$ higher than oxide are found in $\mathrm{Fe}_{4} \mathrm{~N}$ and low $\mathrm{Hc}$ metal powders. Their $\mathrm{Br} / \mathrm{Hc}$ are greater than 2 . We have already reported on the characteristics of $\mathrm{Fe}_{4} \mathrm{~N}$ with respect to magnetic properties, corrosion resistance and electromagnetic characteristics $(3,4,5)$. Therefore, this paper reports on low Hc metal powders and tape. After examining the characteristics of low Hc metal tapes, we successfully developed low Hc metal powders, the os of which was high, while the Hc was about 900 Oe. Furthermore, the powders displayed excellent corrosion resistance. They were tested on 1/2-inch video tape, and their electromagnetic characteristics were measured. Consequently, it has become apparent that the output level and $\mathrm{C} / \mathrm{N}$ level of the tape were higher than those of oxide powder tapes.

\section{EXPERIMENTAL}

2-1. Preparation of low HC metal particles

Acicular $\alpha-\mathrm{FeOOH}$ particles (mean length:0.31 $\mathrm{mm}$, aspect ratio:6.2/1) were prepared by using slightly alkaline $\mathrm{FeSO}_{4} \cdot 7 \mathrm{H}_{2} \mathrm{O}$ solution as the starting material. To prevent sintering during the following reaction at high temperature,

Central research Institute, Taiyo Yuden Co., Ltd. (562 Hongo Tukanaka, Haruna-machi, Gunma-gun, Gunma 370-33)

Key Words: Magnetic Particles, Alloy Particles, Video Tape. 
$\mathrm{SiO}_{2}$ was coated on the $\alpha$-FeOOH particle-surface. The $\alpha$-FeoOH particles were suspended in water, and sodium silicate aqueous solution was added. The addition of $\mathrm{SiO}_{2}$ was 2 wto of the $\mathrm{Fe}$ in FeOOH. After treatment, the pH was adjusted to 5.5. By controlling the $\mathrm{pH}$, $\mathrm{SiO}_{2}$ was coated on the surface of the FeOOH particles. $\mathrm{Ni}\left(\mathrm{NO}_{3}\right)_{2} \cdot 6 \mathrm{H}_{2} \mathrm{O}$ was added to the suspension with vigorous stirring at room temperature, and the $\mathrm{pH}$ was adjusted to 7.8 with aqueous ammonia. Thus, $\alpha-\mathrm{FeOOH}$ particles modified with $\mathrm{Ni}(\mathrm{OH})_{2}$ were obtained. $\mathrm{Co}(\mathrm{OH})_{2}$ modification on the goethite particle-surface was carried out by a similar method. The quantities of $\mathrm{Si}, \mathrm{Ni}$ and $\mathrm{Co}$ contained in the particles were estimated by fluorescent X-ray analysis. The contents of $\mathrm{Ni}$ and co varied from 0 to $60 \mathrm{wt} \%$, and from 0 to $20 \mathrm{wt} \%$, respectively.

The goethite particles were filtered and dried at $150^{\circ} \mathrm{C}$. The particles were then calcined in air at $650^{\circ} \mathrm{C}$ for 1 hour, and reduced in hydrogen at $420^{\circ} \mathrm{C}$ in a rotary kiln. After the reduction process was finished, the sample was immersed in toluene under a nitrogen atmosphere to prevent rapid oxidation, and then the powder was exposed to air until the amount of toluene in the powder was decreased less than $10 \mathrm{wt} \%$ of Fe. The metal powder was spread uniformly in a layer about $1 \mathrm{~cm}$ in thickness in a stainless steel boat, and heated in an oven in air. The surface of the metal particles was slowly oxidized by stepwise heating. The initial heating rate was about $1{ }^{\circ} \mathrm{C} / \mathrm{min}$, and was held for 1 hour for each $10^{\circ} \mathrm{C}$ rise in temperature. When the prescribed temperature was reached, the temperature was kept at this point for 2 hours. The final temperature was $\simeq 100^{\circ} \mathrm{C}$.

2-2. Preparation of $1 / 2$-inch tapes

Magnetic recording tape was prepared by using the alloy powder and the following method. The powders were dispersed in a binder solution using a sand mill, painted on a PET film in a continuous gravure coater, oriented in a magnetic field of 2800 oe, and finally dried. The tape obtained was treated on a hot calender roll and slit into 1/2-inch widths. After calendering the final thickness of the magnetic layer was about $4.0 \mu \mathrm{m}$. The materials used are given below:

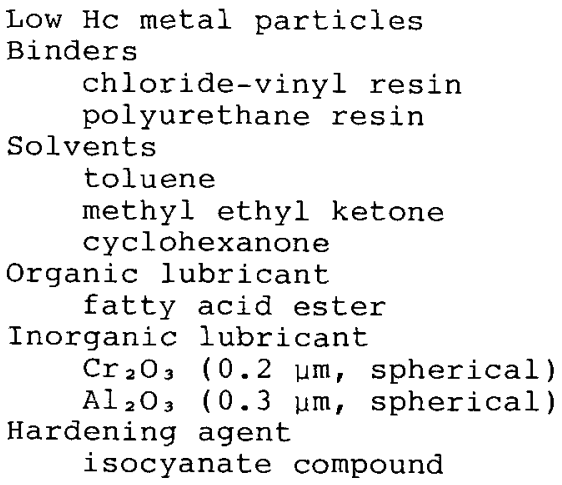

$$
\begin{array}{r}
24.0 \text { wto } \\
1.9 \text { wto } \\
2.7 \text { wto } \\
30.0 \text { wto } \\
30.0 \text { wto } \\
6.7 \text { wto } \\
0.9 \text { wto } \\
1.6 \text { wto } \\
1.5 \text { wto } \\
0.7 \text { wto }
\end{array}
$$

\section{$2-3$. Measurements}

2-3-1. Magnetic properties and stability tests The magnetic properties were measured with a vibrating sample magnetometer under a maximum external field of $10 \mathrm{kOe}$. Stability tests on the powder and the tape were conducted by exposing them to an atmosphere of $90 \% \mathrm{R} . \mathrm{H}$. at $60^{\circ} \mathrm{C}$ for periods of 75 hours and 1 week, respectively. The deterioration values of $\sigma s$ and Bs were determined.
Record Amplifier Ferrite Video Head

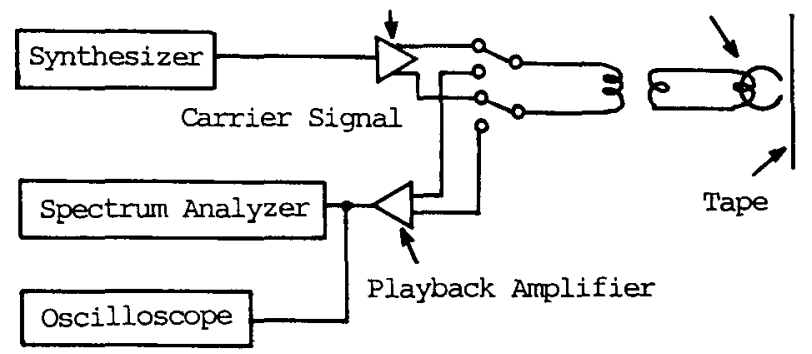

Fig.1 Block diagram of measuring equipment for video recording performance 
2-3-2. Electromagnetic conversion characteristics (luminance output and $\mathrm{C} / \mathrm{N}$ )

To obtain the characteristics as accurately as possible, the measurements were carried out on two video decks with recording-reproducing magnetic heads made of different materials. One was a S-VHS deck (JVC BR-711) with a ferrite head and the other was an ED-Beta deck (SONY EDV-5000) with a sendust head. The RF input-output performance and noise spectra of the tape were measured by using the system as shown in Fig.1 (4). The recording-reproducing amplifier was modified in the above two video decks. The sine wave signal was recorded for various recording current.

The signal was reproduced, and the RF output level is the value of the maximum playback output level measured with a spectrum analyzer (HP 3585A). The noise level was measured at $1 \mathrm{MHz}$ lower than the frequency used to measure the RF output. Measurements were made on frequencies ranging from 3 to 7 $\mathrm{MHz}$.

\section{RESULTS AND DISCUSSION}

3-1. Preparation of low Hc metal particles and improvement in their corrosion resistance

The Hc value of the metal particles was reduced by the addition of $\mathrm{Ni}(7)$. The effect of $\mathrm{Ni}$ addition on the $\mathrm{Hc}$ and $\sigma \mathrm{s}$ of metal particles is shown in Fig. 2 .

When the amount of $\mathrm{Ni}$ addition changed from 0 to 60 wto, $\mathrm{HC}$ and os decreased linearly from 1450 to 935 oe and from 130 to $105 \mathrm{emu} / \mathrm{g}$, respectively. Since not only the $\mathrm{Hc}$ but also os was decreased by $\mathrm{Ni}$ addition we decided to try the cobalt addition as a second additive, because alloys in $\mathrm{Fe}-\mathrm{Co}$ system show the highest os. The effect of Co addition on $\mathrm{HC}$ and os is shown in Fig. 3 .

Figure 3 shows that os increased with increased of $\mathrm{Co}$ and $\mathrm{HC}$ peaked at $10 \mathrm{wt} \%$. The drop in $\mathrm{HC}$ was attributed to a lowering of the shape anisotropy on the basis of TEM observations.

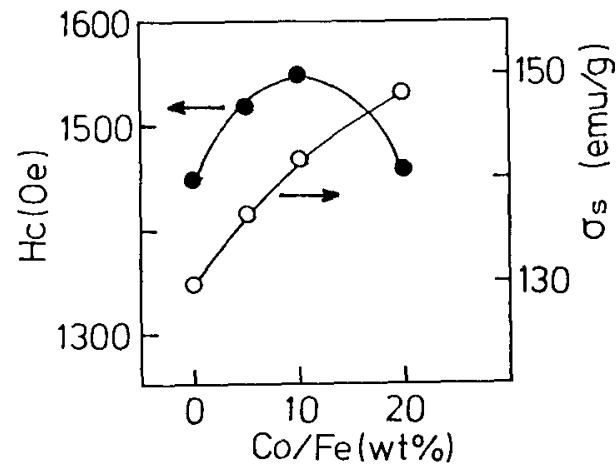

Fig.3 Effect of Co addition on the coercive force $\mathrm{HC}$ (O) and saturation magnetization os (O) of $\mathrm{Fe}$ particles

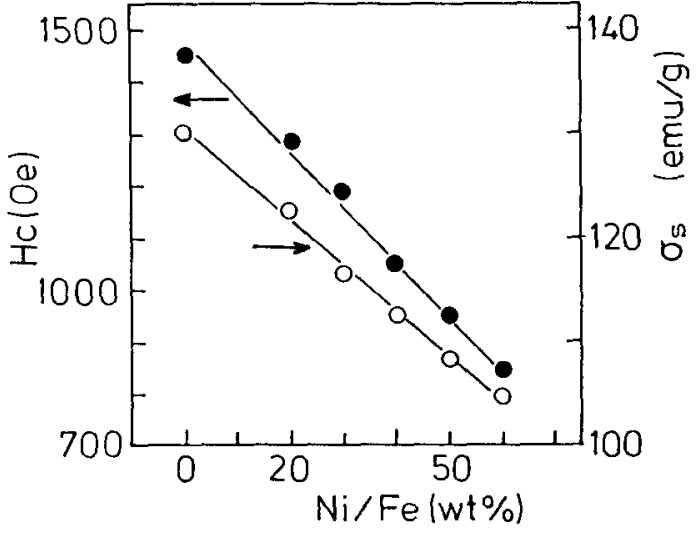

Fig.2 Effect of $\mathrm{Ni}$ addition on the coercive force $\mathrm{HC}(\odot)$ and saturation magnetization os (O) of Fe particles

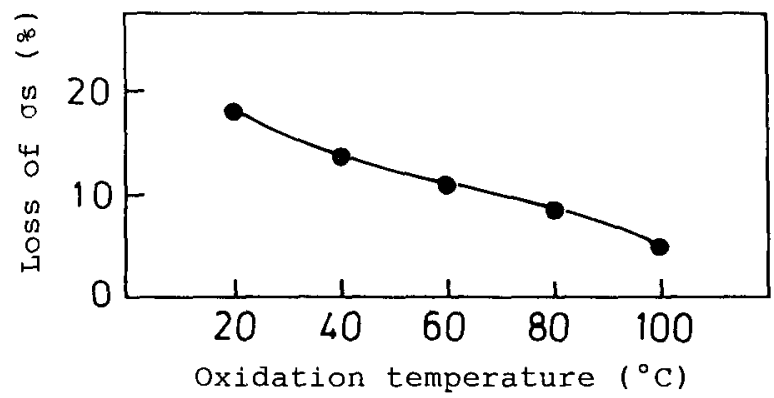

Fig.4 Dependence of loss of saturation magnetization os of $\mathrm{Fe}-\mathrm{Ni}-\mathrm{Co}$ alloy particles on oxidation temperature in humid air $(90 \% \mathrm{R} . \mathrm{H}$.$) at 60^{\circ} \mathrm{C}$ in $75 \mathrm{~h}$ 
The needle-like particles were sintered to give thicker particles. Consequently, the amounts of $\mathrm{Ni}$ ard $\mathrm{Co}$ added had to be controlled to achieve Hc of about 900 Oe and to keep os high. The Hc of about 900 oe and os of above $120 \mathrm{emu} / \mathrm{g}$ were obtained at $55 \mathrm{wt} z$ of $\mathrm{Ni}$ and $5 \mathrm{wt} z$ of Co.

We next studied the effects of thermal surface oxidation to improve corrosion resistance. The loss of os in humid air at $60^{\circ} \mathrm{C}$ after 75 hours for various surface oxidation temperature is shown in Fig.4. The indication was that stability was improved by increasing the oxidation temperature. However, a surface oxidation temperature of $80^{\circ} \mathrm{C}$ is adequate, because of the danger of ignition above $100^{\circ} \mathrm{C}$. Furthermore, judging from the stability levels, it was suitable for use in commercial $8 \mathrm{~mm}$ video tape.

3-2. Characteristics of low Hc metal tape

3-2-1. Magnetic properties The magnetic properties of the tape containing $\mathrm{Ni}$ 55 wts and co 5wtr, with particle surface oxidized at $80^{\circ} \mathrm{C}$, are shown in Table 1. Commercial pro-use VHS tape, S-VHs tape, $8 \mathrm{~mm}$ tape and ED-Beta tape are shown for reference in addition to the alloy tape. $\mathrm{Hc}$ and $\mathrm{Br}$ of the metal tape with low Hc were 953 oe and 2630 G, respectively. Therefore, the value of $\mathrm{Hc} / \mathrm{Br}$ is 2.81, i.e. it is very high and nicely balanced. The loss of Bs was $6 \%$ in humid air at $60^{\circ} \mathrm{C}$ after one week, i.e. it is comparable to or better than that of commercial $8 \mathrm{~mm}$ video tapes.

Table 1. Magnetic characteristics

\begin{tabular}{|l|c|c|c|c|c|}
\hline & $\begin{array}{c}\text { Bs } \\
(\mathrm{G})\end{array}$ & $\begin{array}{c}\mathrm{Br} / \mathrm{Bs} \\
(-)\end{array}$ & $\begin{array}{c}\mathrm{HC} \\
(\mathrm{Oe})\end{array}$ & $\begin{array}{c}\mathrm{D} \\
(\mu \mathrm{m})\end{array}$ & $\begin{array}{c}\text { Loss of Bs } \\
(8)\end{array}$ \\
\hline $\begin{array}{l}\text { pro-use } \\
\text { VHS tape }\end{array}$ & 1650 & 0.812 & 725 & 4.2 & \\
\hline $\begin{array}{l}\text { S-VHS tape } \\
\text { A }\end{array}$ & 1990 & 0.824 & 875 & 4.4 & \\
\hline $\begin{array}{l}\text { S-VHS tape } \\
\text { B }\end{array}$ & 1970 & 0.893 & 950 & 3.2 & \\
\hline $\begin{array}{l}\text { 8mm video } \\
\text { tape }\end{array}$ & 3230 & 0.777 & 1535 & 2.7 & 9.1 \\
\hline $\begin{array}{l}\text { ED-Beta } \\
\text { tape }\end{array}$ & 3410 & 0.868 & 1550 & 2.8 & 2.0 \\
\hline $\begin{array}{l}\text { low HC } \\
\text { alloy tape }\end{array}$ & 3260 & 0.807 & 935 & 4.1 & 6.0 \\
\hline
\end{tabular}

\section{$\mathrm{D}$}

- Thickness of magnetic layer

Loss of Bs : loss of saturation magnetization flux density Bs of tapes in humid air (90\%

R.H.) at $60^{\circ} \mathrm{C}$ after 1 week

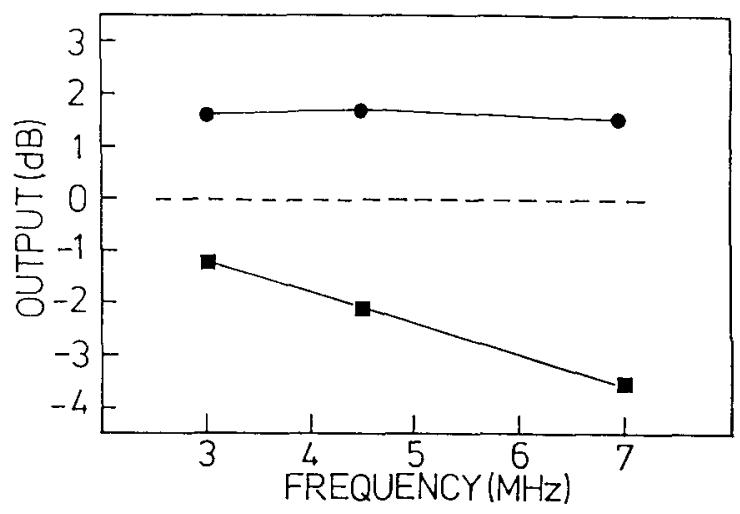

Fig.5 Frequency dependence of RF playback output level with S-VHS deck for a commercial prouse VHS tape ( $\square$ ) and low HC alloy tape (1) on the basis of commercial S-VHS tape (-----)

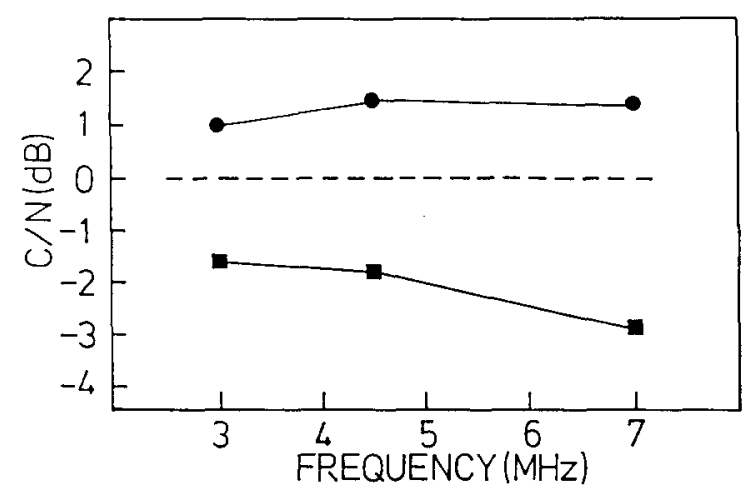

Fig.6 Frequency dependence of $\mathrm{C} / \mathrm{N}$ level with S-VHS deck for the pro-use vHs tape ( $\square$ ) and low Hc alloy tape $(0)$ on the basis of S-VHS tape (-----) 
3-2-2 Video recording performance

The electromagnetic characteristics of the low Hc alloy tape were investigated in detail using a S-VHS video deck with a ferrite recording head.

Figure 5 shows the frequency plots of RF output level obtained using commercial S-VHS tape. The zone of the main luminance signal of S-VHS was from $5.4 \mathrm{MHz}$ to $7 \mathrm{MHz}$. It can be seen that the low Hc alloy tape had a high output level. This was $+1.6 \mathrm{~dB}$ higher than the commercial s-VHS tape and $+4 \mathrm{~dB}$ higher than commercial pro-use vHs tape. Frequency plots of $\mathrm{C} / \mathrm{N}$ level are shown in Fig.6. They also show a high value of $\mathrm{C} / \mathrm{N}$, that is, $+1.5 \mathrm{~dB}$ and $+3.5 \mathrm{~dB}$ higher than $\mathrm{S}$-VHS and pro-use VHS tapes, respectively. The high $\mathrm{C} / \mathrm{N}$ value of low Hc alloy tape is determined by high output level as metal tapes and low noise level as oxide tapes.

The results of the video recording performance of the low Hc alloy tape using an ED-Beta deck with a TSS recording head having high saturation magnetization are as follows. The frequency dependences of RF output and $\mathrm{C} / \mathrm{N}$ level based on S-VHS tape are shown in Figs.7 and 8, respectively. Playback output of

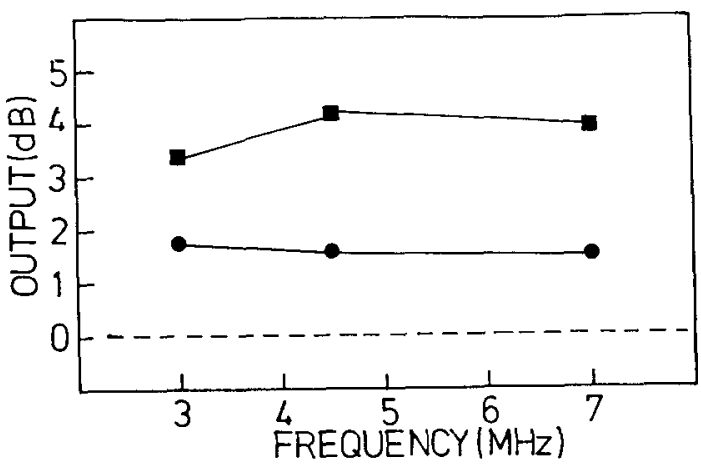

Fig. 7 Frequency dependence of RF playback output level with ED-Beta deck for a commercial ED-Beta tape $(\square ;$ and low HC alloy tape ( ) on the basis of S-VHS tape (--.--)

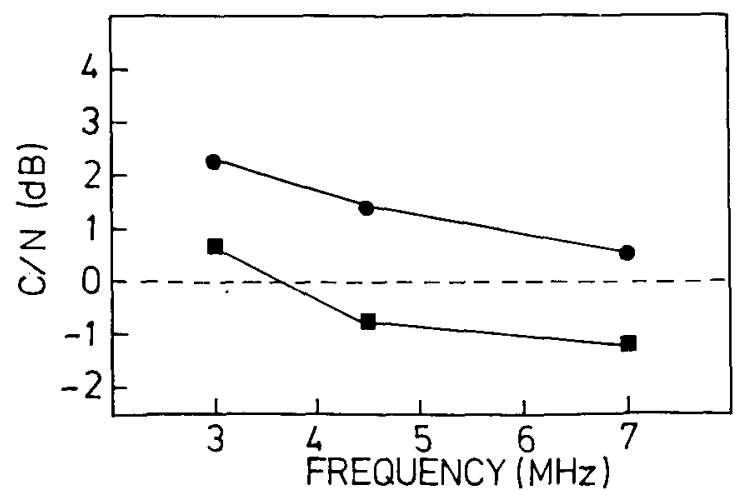

Fig.8 Frequency dependence of C/ $\mathrm{N}$ level with ED-Beta deck for the ED-Beta tape ( $\square$ ) and low Hc alloy tape (O) on the basis of S-VHS tape(-----)

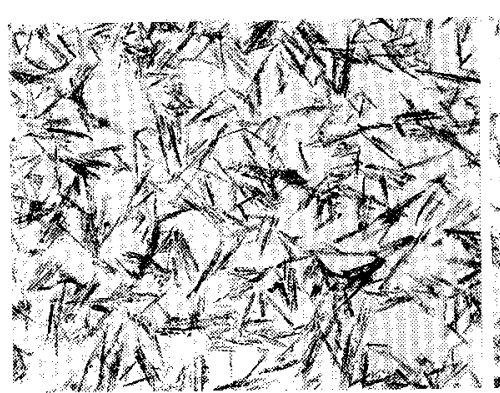

(a)

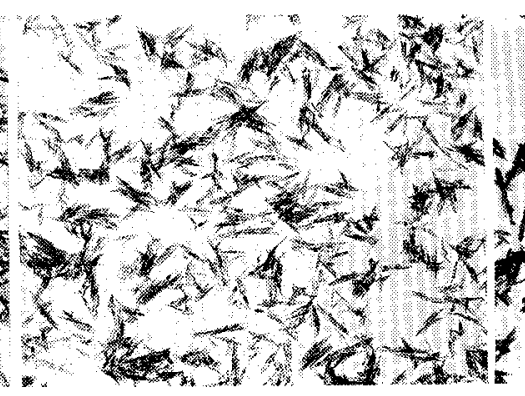

(b)

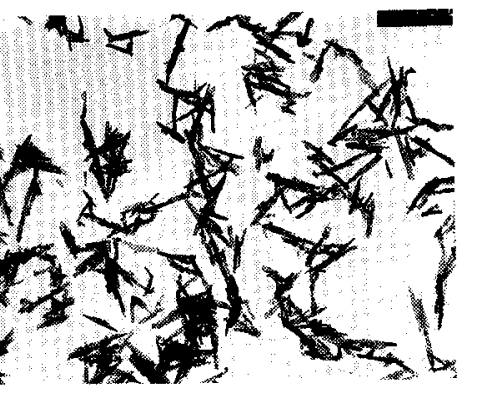

(c)

\section{$1 \mu \mathrm{m}$}

Fig.9 Transmisssion electron micrographs

(a) High HC metal particles for $3 \mathrm{~mm}$ video tape

(b) Low Hc alloy particles

(c) Co-modified $\gamma-\mathrm{Fe}_{2} \mathrm{O}_{3}$ for $\mathrm{S}$-VHS tape 
the low Hc alloy tape was low, less than 2.5 dB on ED-Beta tape with a high $\mathrm{HC}$ of $1500 \mathrm{Oe}$. However, in contrast to the output level, the $\mathrm{C} / \mathrm{N}$ of the tape was higher than that of ED-Beta tape, because the noise was low. Electron micrographs of the high $\mathrm{Hc}$ metal particles for the $8 \mathrm{~mm}$ video tape, the low $\mathrm{Hc}$ alloy particles and Co-modified- $\gamma-\mathrm{Fe}_{2} \mathrm{O}_{3}$ particles for the $\mathrm{s}-\mathrm{VHS}$ tape are shown in Fig. 9 .

Figure 9 shows that the grain size of the alloy particles was smaller than those of metal particles of $8 \mathrm{~mm}$ tape grade and oxide particles for s-vHs tape. The low noise level can be simply explained, because the tape noise is directly proportional to the square root of the grain size. The tape has a low output level compared with that of high Hc metal tape, but the noise level is low because the grain size is small. Therefore, it can be used to obtain a magnetic tape of high $\mathrm{C} / \mathrm{N}$.

\section{CONCLUSIONS}

(1) The HC of acicular metal particles was decreased from 1450 De to 935 Oe by 55 wto $\mathrm{Ni}$ addition $(\mathrm{Ni} / \mathrm{Fe})$ and $5 \mathrm{wt} \%$ Co addition $(\mathrm{Co} / \mathrm{Fe})$ while the os was kept high.

(2) The surface of the metal particles was oxidized by stepwise heating. The corrosion resistance of the magnetic tape was comparable to or better than commercial $8 \mathrm{~mm}$ video tapes.

(3) The measurment of the video recording performance of the tape showed that when measured with a ferrite head at $4.5 \mathrm{NHz}$, the $\mathrm{RF}$ output and $\mathrm{C} / \mathrm{N}$ levels were superior to those of commercial S-VHS tape by $1.8 \mathrm{~dB}$ and $1.6 \mathrm{~dB}$, respectively. When measured with a TSS head at $7 \mathrm{MHz}$, the RF output level was inferior to that of commercial ED-Beta tape by $2.5 \mathrm{~dB}$, but the $\mathrm{C} / \mathrm{N}$ level was superior by $1.6 \mathrm{~dB}$.

\section{REFERENCES}

1). S. Muramatsu, Int. Tv. Eng. Jpn., 34, 1017 (1980).

2). S. Muramatsu, Shikizai Kyokai Shi, 58,204 (1985).

3). N. KItaori, T. Hisanari, H. Ogawa and H. Ohkubo, Denki Kagaku, 55, 773 (1987).

4). N. Kitaori, M. Shinoda, T. Arikawa, H. Ogawa, Denki Kagaku, 55, 936 (1987).

5). N. Kitaori, M. Shinoda, Nippon Kagaku Kaishi, 1682 (1989).

6). S. Matsumoto, Shikizai Kyokai Shi, 57, 602 (1984).

7). N. Kitaori, A. Goto, H. Ogawa, Denki Kagaku, 55, 536 (1987). 